\title{
ECONOMIC CONSEQUENCES OF POPULATION GROWTH
}

\author{
EDWIN BROOKS \\ Department of Geography, University of Liverpool, Liverpool
}

\section{INTRODUGTION}

Population growth has traditionally been regarded as an index of economic buoyancy and material prosperity, but it was only after the spectacular success of the Industrial Revolution that lurking anxieties about such growth began to be dispelled. The Malthusian spectre seemed to have been exorcised by scientific incantations, and the incoming surge of human beings came to appear less as a threat than as a stimulus.

Yet, as the implications of this totally unprecedented demographic explosion began to sink in, the short-lived euphoria of technological mastery began to evaporate. For one thing, the sheer magnitude of growth without parallel in human history invoked some sobering and sombre thoughts about the capacity of the under-developed world to sustain the multiplying millions for whom medical death control had provided many additional years of life expectancy. In the 19th century, in the successfully industrializing nations such as Great Britain, death control had been brought about by a combination of urban hygiene, decontaminated nutrients and water, and a succession of medical advances of which vaccination was one of the early milestones. The process, although dramatic enough by comparison with earlier times, was to straddle a number of generations, and even during the high noon of Victorian population expansion the rate of annual growth remained little more than half that being experienced currently in most of the poor world. Moreover, some relief was afforded by migration to the new lands available for white settlement in temperate latitudes, while before the end of the century a further slackening of the economic strain came with the so-called 'demographic transition'. Put simply, this marks a period of falling birth rates, when both motivation and technical skills combine to offset death control by deliberate family limitation. In effect, extra offspring are exchanged for a better quality of life for the (henceforth) largely surviving brood.

However, in the modern 'developing' world, this combination of circumstances is lacking. Migration is no longer possible on any large scale and the frontiers of the cultivated already press hard upon the potentially cultivable. The crisis is, in fact, fundamental. The processes of death control, far from evolving simultaneously with steady industrialization and economic transformation, have suddenly been visited upon the poor world in one fell swoop. Malaria eradication, the antibiotics, inoculation against diseases such as yellow fever and 
cholera, which once decimated the tropical world, have all arrived in a historical moment. They have arrived in countries where the social as well as the economic infra-structure is rudimentary and is often hostile to investment and accumulation of capital. Even if such domestic problems can be overcome, the international framework is hardly favourable to infant industries striving to penetrate the markets dominated by the entrenched producers. The steadily falling terms of trade against primary producers, and the wildly fluctuating prices of key commodity exports, have further hindered balanced economic growth in the poor world. Yet without such balanced growth, the economies of the developing nations will continue to be distorted by the colonial inheritance of specialized and vulnerable trading rôles.

\section{DEMOGRAPHY}

It took roughly the first three-quarters of the Christian era for the human race to double in numbers (Table 1). The next doubling took 200 years, from the time of the Lord Protector to that of the Great Exhibition in the mid-19th century. Yet the next two doublings have together spanned a mere 125 years, and the present doubling time is little more than a third of a century. This is the equivalent (Table 2) of an annual rate of growth of $2 \%$, which may not sound

Table 1. Population doubling times (after Ehrlich \& Ehrlich, 1970)

\begin{tabular}{|c|c|c|}
\hline Date & $\begin{array}{l}\text { Estimated world } \\
\text { population }\end{array}$ & $\begin{array}{l}\text { Time for population } \\
\text { to double }\end{array}$ \\
\hline \multirow[t]{2}{*}{$\begin{array}{l}8000 \text { B.C. } \\
\text { A.D. } 1650 \\
\text { A.D. } 1850 \\
\text { A.D. } 1930 \\
\text { A.D. } 1975\end{array}$} & $\begin{array}{r}5 \text { million } \\
500 \text { million } \\
1000 \text { million } \\
2000 \text { million } \\
4000 \text { million }\end{array}$ & $\begin{array}{r}1,500 \text { years } \\
200 \text { years } \\
80 \text { years } \\
45 \text { years }\end{array}$ \\
\hline & $\begin{array}{l}\text { Computed doubling } \\
\text { time around } 1970\end{array}$ & 35 to 37 years \\
\hline
\end{tabular}

Table 2. Population growth rate (after Ehrlich \& Ehrlich, 1970)

\begin{tabular}{c|c}
\hline Annual \% increase & Doubling time (years) \\
\hline 0.5 & 140 \\
0.8 & 87 \\
1.0 & 70 \\
2.0 & 35 \\
3.0 & 24 \\
4.0 & 17 \\
\hline
\end{tabular}

too alarming until we translate it into an increment of three billion over three decades. Even if population increase were to be halved to a figure of some $1 \%$ annually, it is clear from Text-fig. 1 that this would give little more than 
an extra 150 years before there was one inhabitant per square metre. At the present rate, this 'impossible' state of affairs would be reached by approximately the beginning of the 23 rd century; at the $1 \%$ rate, by the middle of the 25 th century.

But this, of course, is simply playing a numbers game, and demonstrating the well-known terror of compound interest (or, as Malthus might have put it,

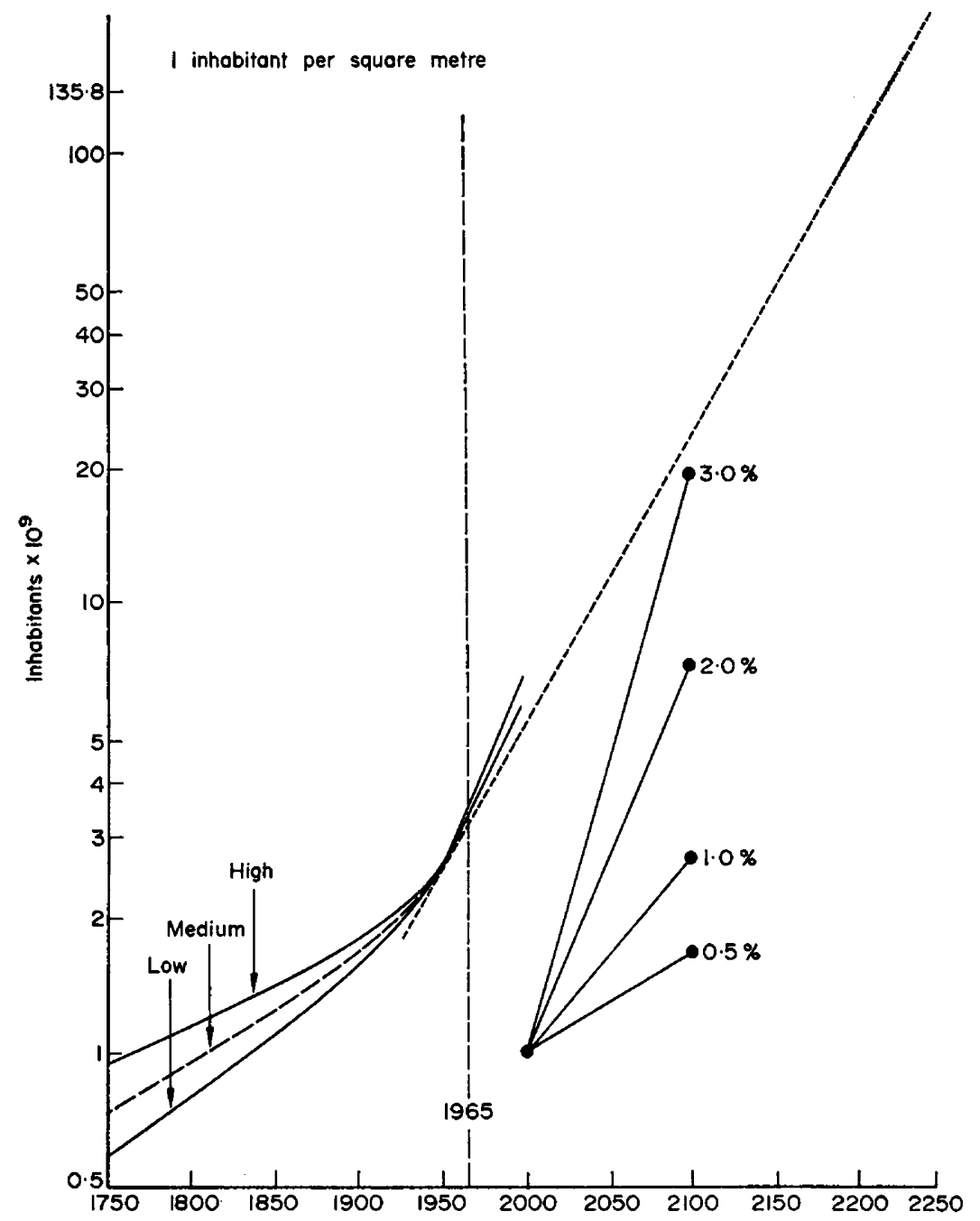

TExT-FIG. 1. World population growth, 1750-2000, showing high, medium and low estimates. Average annual increase rates are marked for comparison. (After Clarke, 1968.)

geometrical progression). What we have to consider is the reliability of such automatic extrapolations, and the likelihood of a demographic transition occurring in the poor world. More specifically, the question is not so much whether such a transition will eventually materialize, but how rapidly and 
effectively it will happen. And here, it must be admitted, our techniques of long-term forecasting are about as reliable as the use of tea-leaves to prophesy the arrival of strangers.

The basic problem is to assess the time-lag between death control and birth control, and this will clearly depend upon a host of mutually related factors ranging from educational advance and family motivation to contraceptive devices and economic stimuli. Such factors may be transformed by unforeseen and strictly unforeseeable changes, and it would be hazardous to peer very far into the future. Nevertheless, in the short-term, which means during the remainder of this century, it is possible to project population figures with reasonable confidence, if only because most of the potential parents of this century have already been born and enumerated. The spreading bases of the population pyramids for the poor countries, which mark the consequences of falling infant and maternal mortality, will inexorably move up the pyramid as the years go by. This will mean a substantially larger cohort of potential parents a generation hence than in the corresponding age range of today, and, unless family size is very sharply reduced from its present level, the next parental generation will in turn send a demographic impulse-through its own offspring-a further 30 years ahead into the 21 st century.

\section{UNEMPLOYMENT}

The numerical implications of this growth, which lead us to anticipate about a billion extra people per decade between now and A.D. 2000, suggest that the major problem of the coming years will be that of coping with a multitude of economically unnecessary individuals. However much we stimulate intermediate technology in the developing countries-and so far only China seems to have had much success in this-it seems distinctly optimistic to foresee anything but massive unemployment (and concealed under-employment) in the decades ahead. Manufacturing industry, which for predominantly agricultural peasant societies seems the prerequisite of economic transformation and higher individual wealth, works generally more efficiently with a high capital-labour ratio, and certainly if the developing nation wishes to penetrate competitive world markets it can hardly afford to ignore the advantages of highly mechanized continuousflow techniques.

\section{URBANIZATION}

Again, in contrast to the experience of the present 'rich' world, the urbanization process in the poor world is only tenuously related to successful transition to industrial economy. As shown in Table 3, which is based on United Nations (1969) data, there has been a spectacular increase in the number of major urban concentrations in the poor world during the middle decades of this century; yet many of these cities are little more than aggregations of the unwanted. As agriculture proves incapable of sustaining the growing peasant masses, they move to the town where they huddle in squalor, poverty and idleness. The shanty towns and the favellas are the symptoms of a quasi-urbanizing process which seems destined to produce social deprivation and political violence. 
Table 3. Major urban concentrations, 1920 and 1960

\begin{tabular}{|c|c|c|c|c|}
\hline & \multicolumn{2}{|c|}{1920} & \multicolumn{2}{|c|}{1960} \\
\hline & $\frac{1}{2}$ to $2 \frac{1}{2}$ million & $>2 \frac{1}{2}$ million & $\frac{1}{2}$ to $2 \frac{1}{2}$ million & $>2 \frac{1}{2}$ million \\
\hline $\begin{array}{l}\text { North America } \\
\text { South America } \\
\text { Europe } \\
\text { Asia } \\
\text { Africa } \\
\text { Australia }\end{array}$ & $\begin{array}{r}17 \\
4 \\
37 \\
13 \\
1 \\
2\end{array}$ & $\begin{array}{l}2 \\
0 \\
3 \\
1 \\
0 \\
0\end{array}$ & $\begin{array}{r}37 \\
12 \\
78 \\
64 \\
9 \\
4\end{array}$ & $\begin{array}{l}4 \\
3 \\
5 \\
9 \\
1 \\
0\end{array}$ \\
\hline
\end{tabular}

The lack of employment, in turn, curtails the domestic market and discourages investment by both local and external entrepreneurs. Investment instead tends to focus on the 'bonanza' areas of rich mineral strikes, where high profits and capital-intensive extraction are the norm. Nevertheless, however povertystricken the urban masses are, and however unproductive, they continue in aggregate to consume the resources of the poor country. As their numbers swell, so the already slender economic surplus is eroded further. Against this summary background of the predicament of the developing world, it is increasingly difficult to avoid the sense of a looming catastrophe as the century draws towards its close.

It must be accepted, of course, that the developing world is far from a homogeneous unit. Guyana, say, with its 800,000 people clustered on a narrow coastal strip backed by an empty interior, may seem a far cry from India whose numbers rose from 439 million in 1961 to 547 million 10 years later. Yet at the risk of over-simplification, in most of the inter-tropical world there are common problems of climate, soils and inherited social structures which make all these countries incapable of reconciling a $2 \%$ rate of population growth with economic transformation and material improvement for the bulk of their people. In such countries, with few if any exceptions, population restraint is urgently required in the coming decade if disaster and bitter disappointment are to be avoided.

This plea, however, is now very much the conventional wisdom, and it has been reiterated only to remind us that wisdom without appropriate action becomes folly. And it is still the case that few of the influential decision-makers in the affluent world have grasped the magnitude of the population crisis which is inevitably bound to deepen in the immediate future. As Dr Malcolm Potts shows in his account of the work of the IPPF (p. 475) the priority given to family limitation internationally is lamentably low and, as we know, the Roman Catholic Church is still (officially) hostile to contraception.

Perhaps this mood of official complacency or indifference will change as population begins to move into the main-stream of political controversy in the rich countries. For the population crisis is, in the ultimate, indivisible, and the case for population restraint is no less urgent in the rich world than in the poor. Economy, in the final analysis, is a relationship between man and his environment, and if the poor world needs to ease demographic pressures for the sake of that relationship, so too does the rich world. 


\section{DEPENDENCY}

Before turning to the environmental aspects of population growth in the high consumption economies, it may be noted that there are many different facets to the demographic dilemma facing such countries. For example, the demographic transition of earlier decades in the United Kingdom has resulted in a steadily rising ratio of elderly dependants to the population of working age. As Table 4

Table 4. The dependency ratio per 1000 population of working ages (after Thompson, 1970)

\begin{tabular}{|c|c|c|c|c|c|c|}
\hline & \multicolumn{3}{|c|}{ Census figures } & \multicolumn{3}{|c|}{ Projections } \\
\hline & 1911 & 1941 & 1969 & 1981 & 1991 & 2001 \\
\hline $\begin{array}{l}\text { Children } \\
0 \text { to } 14 \text { years }\end{array}$ & 496 & 312 & 396 & 401 & 411 & 407 \\
\hline $\begin{array}{l}\text { Retirement ages } \\
60 \text { and over (women) } \\
65 \text { and over (men) }\end{array}$ & 110 & 175 & 259 & 276 & 264 & 235 \\
\hline Dependency ratio & 606 & 488 & 655 & 677 & 675 & 642 \\
\hline
\end{tabular}

shows, this has risen from $110 / 1000$ in 1911 to $259 / 1000$ in 1969 , and the figure will continue to rise to a maximum of $276 / 1000$ in 1981 . Thereafter it will fall slightly, partly owing to the impact of the post-1955 rise in the birth-rate (itself an unexpected and certainly unforeseen bulge which remained pronounced until the mid-sixties) upon the working population of the eighties and nineties. The economic implications of these changing patterns are difficult to assess, but it may be suggested that the increasing tendency towards premature retirement is a hint that people in the affluent world, no less than in the poor, are becoming unnecessary to the economic process--and even a hindrance to its efficient operation. Yet, at the very time when such labour-shedding is being encouraged (perhaps the steady raising of the school-leaving age has a similar rôle in reducing explicit unemployment), increasing numbers of people survive to old age. One hesitates to speculate on the size of the redundant populationlet alone its functions - should the ageing process ever be mastered.

This is not, of course, to argue that people should not be allowed to live out their full term-but it does raise the question whether the human race is well advised to strive to extend its personal life-span. Human clustering in Britain has produced exceptionally dense urban populations, particularly in the 'axial belt' which straddles England from the Thames to the Mersey. Within this area of dense population, accentuated by inward migration and (more recently) by substantial growth in situ, we have seen the motor vehicle 'activate' the residents in a way which has worsened the man/land relationship. It is instructive, in this matter of crowding, to compare England and Wales as a whole-and not simply the axial belt - with the famous 'Megalopolis' defined in the north-eastern U.S.A. As Table 5 shows, the entire area south of Hadrian's Wall is already broadly comparable with the American region; on this basis, the axial belt deserves a term all to itself. 
Table 5. Land and population in 'Megalopolis', North-eastern U.S.A. and in England and Wales (after Best \& Champion, 1970)

\begin{tabular}{l|c|c}
\hline & $\begin{array}{c}\text { North-eastern seaboard, } \\
\text { U.S.A. }\end{array}$ & England and Wales \\
\hline Total area & $138,700 \mathrm{~km}^{2}$ & $151,700 \mathrm{~km}^{2}$ \\
Population & $37,000,000(1960)$ & $46,000,000(1961)$ \\
Density & 270 persons $/ \mathrm{km}^{2}$ & 300 persons $/ \mathrm{km}^{2}$ \\
Land use (\% total area): & & 79 \\
$\quad$ Agriculture & 33 & 7 \\
$\quad$ Forest and woodland & 52 & 14 \\
\hline Urban and other uses & 15 & 79 \\
\hline
\end{tabular}

Meanwhile, a process of micro-geographical sifting within the cities has mirrored the wider regional sifting which led to marked economic disparities and social gulfs within the British Isles as a whole. As the towns explode across the former countryside, the inner areas are left as ghettos of the socially and economically-which often means mentally-inadequate. For such ghetto denizens, the economy of affluent meritocratic man can find little use, except in menial and poorly paid jobs; in effect, the favella mentality takes root in the decaying cores, rather than in the outskirts, and the experience of the United States shows how grave this sifting can become when allied to racial differences.

\section{ENVIRONMENT}

Population growth and flux, in other words, have presented the rich world with a crop of problems, some of which have analogues in the poor world. But the essential case for zero growth, and a less frenetic and thrusting economic society, rests on environmental arguments. The Malthusian thesis, it will be recalled, held that, where land was finite, the law of diminishing returns would inevitably operate to constrain the size of the population subsisting upon that finite resource. It also held that population would tend to exist at subsistence level only, since any surplus available would be swallowed up by the increase in numbers which it had evoked. Thus, in Text-fig. 2, at the technology level represented by the food production line $\mathrm{OR}$, the population is restricted to $\mathrm{Xb}$. Any increase above that would mean that the food supply Sb failed to increase sufficiently to maintain the subsistence level represented by OS, and by definition the surplus population would die. If the population fell below $\mathrm{Sb}$, there would be a surplus food output above subsistence level, and the population would tend to rise accordingly.

If the food production were increased by an improved technology $\mathrm{OR}^{1}$, however, a fresh population ceiling, Xc, could be attained, but this too would live only at subsistence level. Without wishing to accept all the assumptions of this model-particularly that which alleges a maximizing rather than an optimizing of population size at a given technology level-it is possible to see a link between Malthus and the modern concept of a world of finite resources where the law of diminishing returns holds sway. The question which remains, 
however, is whether the OR lines can be indefinitely raised to permit increases in the population ceiling-despite the finiteness of the planet.

To this there can be no easy answer, since future scientific and technological discoveries cannot possibly be foreseen. But it must be recognized that the human loading upon the planetary habitat is already on a scale beyond all previous experience, and that environmental degradation is being caused by both the

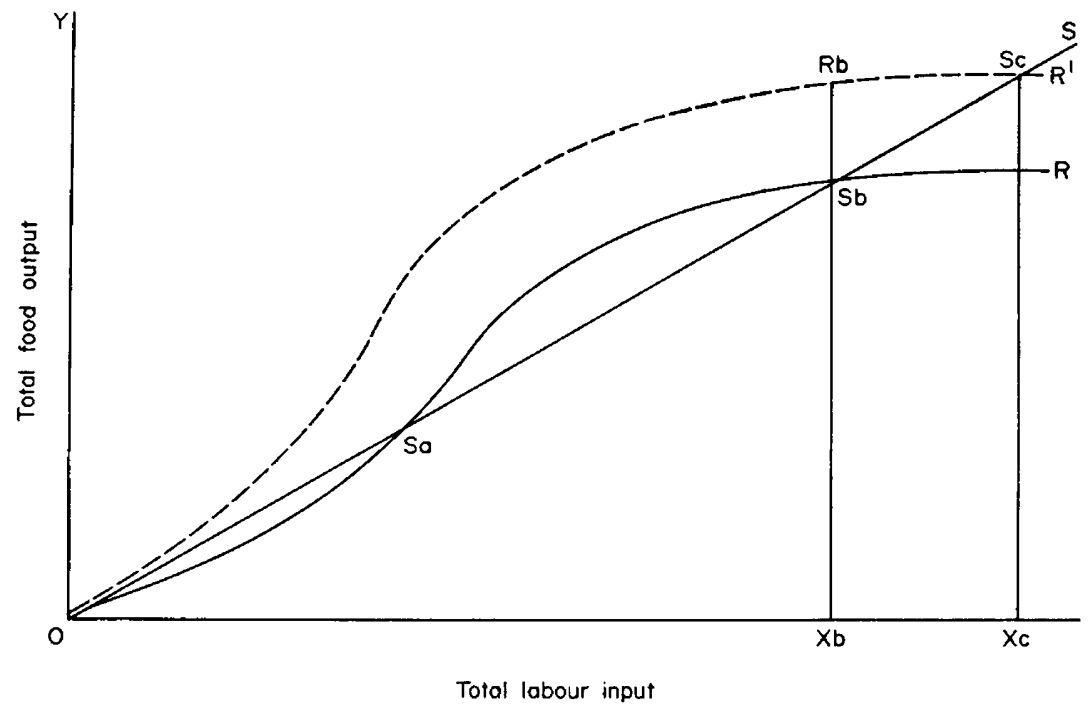

TEXT-FIG. 2. Malthusian model and technological progress (Wagner et al., 1971). OS = subsistence line; $\mathrm{Xb}=$ population ceiling for technology level $\mathrm{OR} ; \mathrm{Xc}=$ population ceiling for technology level $\mathrm{OR}^{1}$.

input demands and the output discharge of consumer society. As Text-fig. 3 shows, the size of the arcs which represent the environmental degradation will vary with greater efficiency in the use of resources, better re-cycling, and changes in per-capita exploitation. But whatever changes may take place in such respects, it is self-evident that population increase will over-ride all the likely economics and improvements in the decades ahead. Moreover, as the poor world strives to emulate the affluence of the present-day rich world, and as that rich world continues to increase its GNP, so the environment will be subject to much greater potential strains than those of today.

To tackle this planetary crisis will require a co-ordinated approach which recognizes, as Text-fig. 4 tries to summarize, the interdependence of the institutional forces and constraints which bear upon it. The variables are allocated under three major headings, with the sensitive action areas listed accordingly. Flanking the key decision-making political and economic structures of the given society we see a symmetrical grouping of critical resource and population components. The symmetry is deliberately intended, and each of the action areas has its twin under the opposite heading. Thus we can draw a parallel between the input (and conservation) of resources and the birth-input (and 


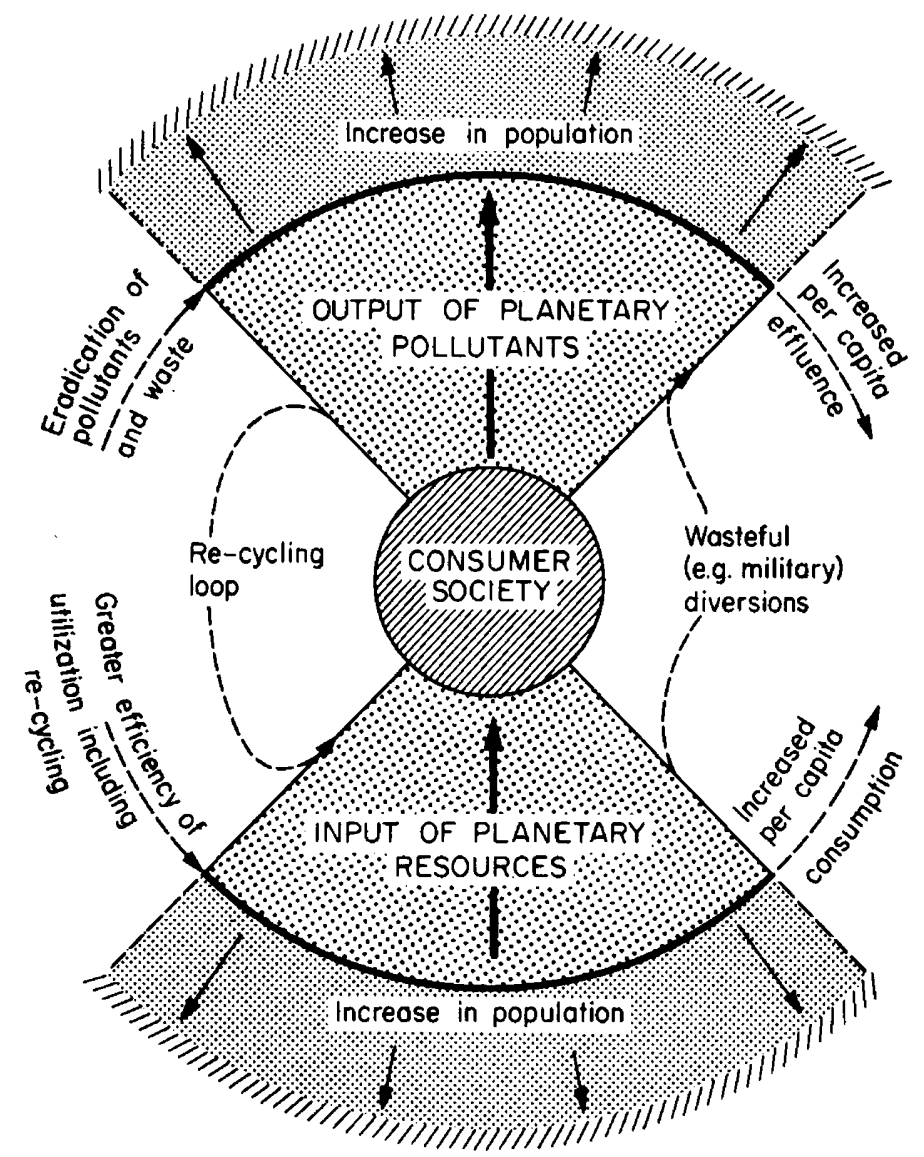

\footnotetext{
Present degradation of biosphere

/ $/ / / / / / / / / / / / / /$ Future degradation due to population increase assuming other variables constant
}

TEXT-FIG. 3. Environmental degradation.

limitation) of human beings. Similarly, the transformation of output, by reducing wasteful effluent, is reminiscent of efforts to eliminate death as the great waster of human life.

The diagram, despite its obvious simplification of a complex situation, points to the multi-dimensional character of the population/resources predicament which different societies apprehend in so many different ways. In some countries the major attack by conservationists and birth controllers may have to be directed initially at the unrestricted and mindless market pressures which produce conspicuous waste and extravagance. In all probability, however (and this is a plea for recognition of the inherent complexity of the crisis we face as a species), there will be need for concerted attack on a broad front, with recognition that the struggle will not be easy in any sector. 


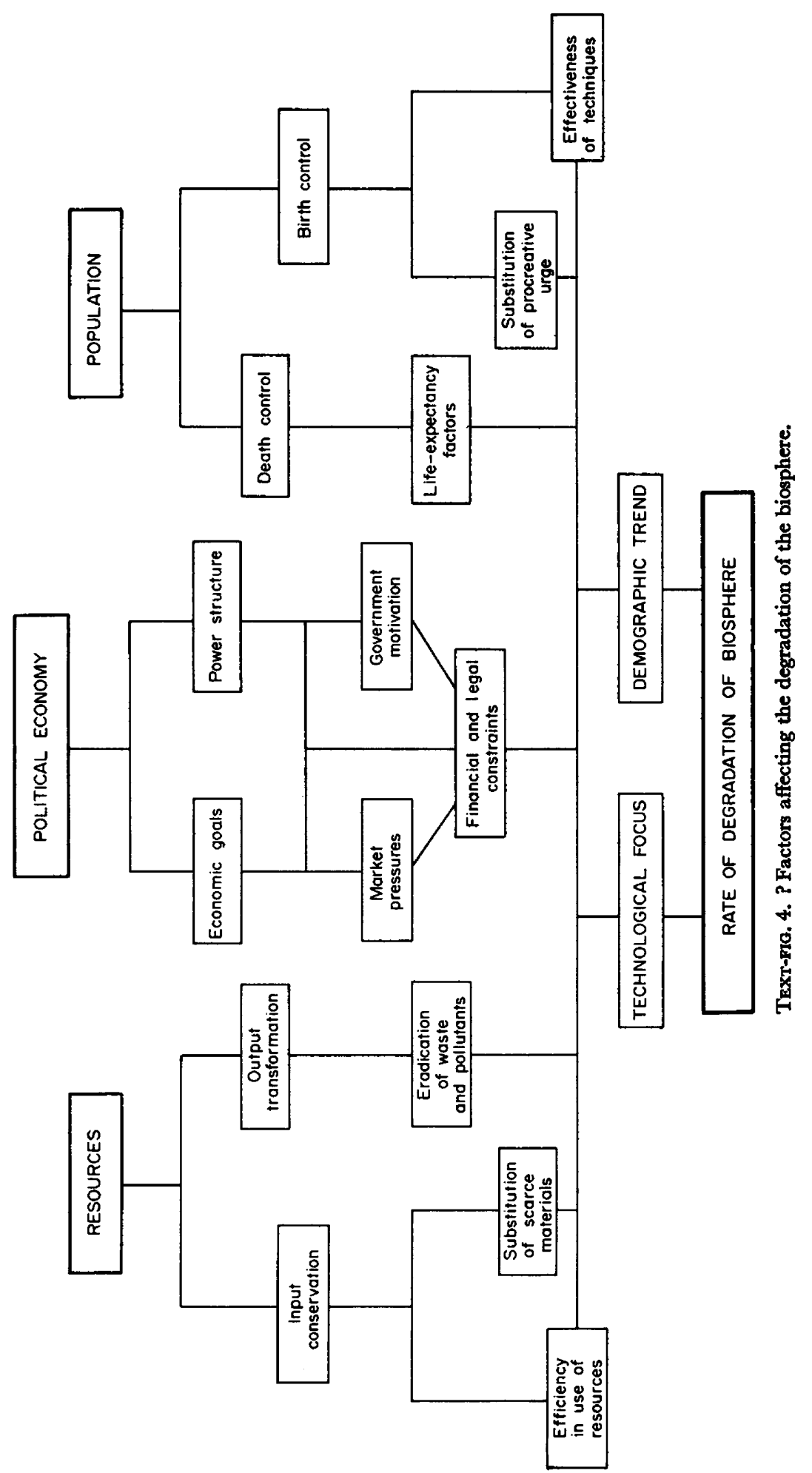




\section{REFERENCES}

Best, R. H. \& Champron, A. G. (1970) Regional conversions of agricultural land to urban use in England and Wales. Trans. Inst. Br. Geogr. 49, 27.

Clarke, J. I. (1968) World population and food resources: a critique. Trans. Inst. Br. Geogr. Special Publication, 1, 57.

Ehrlich, P. R. \& Ehrlich, A. H. (1970) Population, Resources, Environment. W. H. Freeman \& Co., San Francisco, California.

PotTs, D. M. (1974) The implementation of family planning programmes. F. Reprod. Fert., $37,475$.

Thompson, J. (1970) The growth of population to the end of the century. In Social Trends, 1, 21. Central Statistical Office, HMSO.

United Nations (1969) Growth of the World's Urban and Rural Populations. U.N., New York.

Wagner, L., Drake, M., Learmouth, A., Finnegan, R., Murray, D. \& Brown, H. (1971) The Population Explosion-An Interdisciplinary Approach. Open University Press, Walton Hall, Bletchley, Bucks. 